\title{
Trainees Corner
}

\section{Banding in F2 general practice posts}

\author{
Yin Chi Shiba Poon \\ Fifth Year Medical Student, Queen Mary, University of London, UK \\ Peter Dennis Toon \\ Head of Postgraduate Education, Barts and the London Medical School, UK
}

\section{Key messages}

- There are educational benefits in Foundation Year 2 general practice posts

- Junior doctors experienced financial difficulties from the lack of banding payments in these posts

- Low payment is a disincentive for doctors when choosing their rotations
- Changes made to the working hours and the antisocial nature of the posts may qualify doctors for higher banding

Keywords: family practice, foundation training, income
General practice (GP) posts in Foundation Year 2 (F2) were introduced in 2006. A few studies have given us an insight into how junior doctors view GP posts but this topic has not been explored thoroughly. ${ }^{1-3}$

Five doctors were interviewed as part of a BMedSci project to explore their experiences of F2 GP placements. ${ }^{4}$ These interviews, plus two additional interviews with hospital doctors working in London who completed their foundation training in 2007, raise an important practical issue about these posts.

Most of the findings were consistent with the literature. ${ }^{5,6}$ The doctors felt they gained a better understanding of primary care and became more sympathetic towards GP referrals. Their knowledge on common and chronic diseases was broadened and they became more aware of social and psychological aspects of patient's problems. All doctors interviewed felt that GP placements can benefit not only those who plan to become GPs but also future hospital clinicians.

A significant drawback never previously discussed is payment. Junior doctors' pay consists of a basic salary and a supplement calculated according to number of hours worked and the antisocial nature of their work. ${ }^{7}$ F2s in general practice work up to 40 hours per week Monday to Fridays between $8 \mathrm{am}$ and $7 \mathrm{pm}$, and so receive only the basic salary; whereas doctors in other $\mathrm{F} 2$ posts work up to 48 hours per week including shifts and receive an extra banding payment of $20-50 \%$ of the basic salary.

The doctors explained the financial difficulties they experienced working in general practice:

'Before we started the job we were told it would still be a banded job and that we would get at least 50\%, 60\% but when I started they said actually they are making it unbanded. A lot of them didn't take it well because we lost a lot of money... A lot of people applied for the jobs with mortgages and kids... and they couldn't afford because of the low pay... you go from $60 \%$ banding to $0 . .$. so it was a big drop... Your payment was down by 700 pounds or something... and if it wasn't for that I think it would have been easier.' (Doctor 1)

'It was just difficult to make ends meet... I live quite far away... you can imagine paying rent and with the petrol prices now, it's going to be difficult. I think anyone would struggle with an unbanded job.' (Doctor 2)

The salary difference between GP posts and other posts was a discouraging factor when considering their F2 rotations.

'It's just a basic salary... That is perhaps why a lot of people will not choose GP even though they would like to become a GP later... they do not want to risk financially.' (Doctor 3)

This disadvantage may make target recruitment rates difficult to achieve unless F2s are forced to train in GP. One of the doctors who unwillingly worked in GP expressed his dissatisfaction and frustration:

'... It was assigned to mine like all my cohort, it was... a bit underhand really. They brought it in that everyone must do it.' (Doctor 1)

The advantages of GP posts are not only the clinical training; regular working hours allow them to undertake further educational courses, self-directed learning and complete publications. Time can also be spent on personal and family life, improving their work-life balance. On the other hand the disadvantage of a lower salary makes these posts unattractive to junior doctors. 
This problem may be difficult to tackle, as it depends on local funding and negotiations between relevant governing bodies, but there are possibilities worth exploring for banding GP posts.

- With the recent amendment to the GP contract encouraging extended opening hours, F2 doctors could do evening or weekend shifts. However GP surgeries are only paid to extend their opening hours by 30 minutes per week for every 1000 registered patients, ${ }^{8}$ so this may not provide sufficient hours to qualify for higher banding.

- F2s could work additional sessions in GP out-ofhours services or walk-in centres, although this would raise additional complexities in organising accreditation of teachers and clinical supervision.

- A\&E placements could be combined with GP posts so that F2s do a mixture of A\&E shifts and GP clinics. The A\&E shifts may entitle doctors to banding payments.

Planners of future postgraduate medical education should take account of this problem so that future F2s can benefit from GP training without financial disincentives.

\section{ETHICAL APPROVAL}

Ethical approval for this study was obtained from Barking and Havering Local Research Ethics Committee. REC number: 08/H0702/23.

\section{ACKNOWLEDGEMENTS}

This study was made possible by the support from Queen Mary, University of London. I am grateful to Vishalli Ghai for her partnership in conducting the BMedSci project and I would like to thank all the participants for taking part.

\section{REFERENCES}

1 Woodcock I. Foundation Year 2: changing attitudes towards general practice. British Journal of General Practice 2006; 56(532):895.

2 Dobson R. General Practice for foundation doctors: an easy option? British Journal of General Practice 2007; 57(537):331.

3 Abusin S. Foundation programme in general practice. BMJ Career Focus 2006; 333(7571):135.

4 Ghai V and Poon YCS. Follow-up of F2 General Practice Experience. Queen Mary, University of London, 2008 (unpublished dissertation).

5 Illing J, van Zwanenberg $\mathrm{T}$, Cunningham WF et al. Preregistration house officers in general practice: review of evidence. BMJ 2003;326(7397):1019-22.

6 Brennan M, Mountford B and Coles C. Final Report of an Evaluation of the Foundation Programme in Postgraduate Medical Deanery for Kent Surrey and Sussex. Postgraduate Deanery for Kent, Surrey and Sussex, 2006.

7 Department of Health. Junior Doctors Contract-A general guide to the new pay system. 2000, available at: www.dh.gov. uk/en/Managingyourorganisation/Humanresourcesand training/ModernisingPay/JuniorDoctorContracts/DH 4053873 (accessed 10 September 2008).

8 Department of Health. Extended Hours Access Scheme Directed Enhanced Service. 2008, available at: www.dh.gov. uk/en/Publicationsandstatistics/Publications/Publications PolicyAndGuidance/DH_087557 (accessed 10 September 2008).

\section{ADDRESS FOR CORRESPONDENCE}

Yin Chi Shiba Poon

Fifth Year Medical Student

Queen Mary, University of London

Email: ha03133@qmul.ac.uk 